\title{
REFLEXÕES (IM)PERTINENTES NA INTERFACE EXTENSÃO/DIÁLOGO INTERCULTURAL: OUTRAS MIRADAS POSSÍVEIS PARA O TRIPÉ ENSINO- PESQUISA-EXTENSÃO?
}

Barbara E. B. Cabral ${ }^{67}$

\section{Resumo}

Refletir sobre possíveis intersecções entre extensão e diálogo intercultural, tomando como matéria-prima experiências como docente em Instituição de Ensino Superior no sertão do São Francisco, possibilitou a gestação de um ensaio fundado no interesse sobre as fronteiras entre extensão/ensino/pesquisa, que realça a fertilidade do encontro entre os termos, antes que sua separabilidade. A partir da trajetória de pouco mais de uma década de atuação pedagógica, matizada pela inserção em diversos projetos voltados à formação profissional em saúde, discute-se a potência da extensão como via de enriquecimento do ensino e fonte de questões de pesquisa relevantes, destacando-se uma imbricação heurística do tripé. Por fim, toma-se a valorização da experiência, do encontro entre as pessoas e da ativação do sensível - para além da racionalidade - como caminho primordial ao delineamento de processos educativos prenhes de sentido ético-político, no panorama de uma formação cidadã.

Palavras-chave: Extensão. Formação Profissional. Docência. Relações Interpessoais. Grupos de Encontro.

\section{RIFLESSIONI (IM)PERTINENTI NELL'INTERFACCIA RESPONSABILITÀ SOCIALE DELL'UNIVERSITÀ/DIALOGO INTERCULTURALE: ALTRI SGUARDI POSSIBILI PER IL TREPPIEDI DIDATTICA-RICERCA-TERZA MISSIONE?}

\section{Sintesi}

Riflettere sulle possibili intersezioni tra terza missione accademica e dialogo interculturale, prendendo come materia prima esperienze come docente in un istituto di istruzione superiore nel Sertão del São Francisco, ha permesso la creazione di un saggio basato sull'interesse rispetto ai confini tra terza missione / insegnamento / ricerca, che evidenzia la fertilità dell'incontro tra i termini, piuttosto che la loro separabilità. Dalla traiettoria di poco più di un decennio di attività pedagogica, sfumata dall'inserimento in diversi progetti finalizzati alla formazione professionale in salute, si discute la potenza della terza missione come una via di arricchimento dell'insegnamento e fonte di domande di ricerca rilevanti, evidenziando una sovrapposizione euristica del treppiede. Infine, si considera la valorizzazione dell'esperienza dell'incontro tra le persone e l'attivazione del sensibile - al di là della razionalità - come cammino primordiale nel delineare i processi educativi pregni di senso etico-politico, nel panorama di una formazione alla cittadinanza.

\footnotetext{
${ }^{67}$ Docente do Colegiado de Psicologia e das Residências em Saúde da Universidade Federal do Vale do
} São Francisco (Univasf), Campus de Petrolina-PE. 
Parole chiave: Terza missione universitaria. Qualificazione professionale. Docenza. Relazioni interpersonali. Gruppi di incontro.

\title{
(IM)PERTINENT REFLECTIONS ON THE UNIVERSITY SOCIAL RESPONSIBILITY / INTERCULTURAL DIALOGUE INTERFACE: OTHER POSSIBLE LOOKS AT THE DIDACTIC-RESEARCH-THIRD MISSION TRIPOD?
}

\begin{abstract}
Reflecting on the possible intersections between the third academic mission and intercultural dialogue, taking as a raw material, my experiences as a professor of an higher education institution in the Sertão of São Francisco, allowed the creation of an essay based on the interest about the boundaries between third mission / didactic / research, which highlights the fertility of the encounter between the terms, rather than their separability. The power of the third mission is discussed from the trajectory of just over a decade of pedagogical activity, blurred by the inclusion in various projects aimed to professional health training, as a way of enriching teaching and a source of relevant research questions, highlighting a heuristic overlap of the tripod. Finally, we consider the enhancement of the experience of the encounter between people and the activation of the sensitive - beyond rationality - as a primordial path in outlining the educational processes imbued with an ethical-political sense, in the panorama of citizenship training.
\end{abstract}

Keywords: University third mission. Professional qualification. Didactic. Interpersonal relationships. Meeting groups.

\section{Do solo de onde brota o ensaio}

... atribui-se a Voltaire - que outra hora, diz ser a mesma amiúde "o romance do espirito" - a estrafalária seguinte definição de "metafisica: "é um cego, com olhos vendados, num quarto escuro, procurando um gato preto... que não está lá." Seja quem seja, apenas o autor da blague não imaginou é que o cego em tão pretas condições pode não achar o gato, que pensa que busca, mas topar resultado mais importante - para lá da tacteada. E vê-se que nessa risca é que devem adiantar os koan do Zen.

(Rosa, 2001)

Este ensaio se perfilou a partir de uma provocação para integrar uma mesaredonda sobre o tema "Extensão e diálogo intercultural - interseções", no contexto do I Colóquio Internacional Brasil-Itália, ocorrido em agosto de 2019, voltado a discutir "Educação contextualizada e diálogo intercultural na implementação de novas estratégias de internacionalização da extensão". O evento foi promovido pelo Programa de PósGraduação Mestrado em Educação, Cultura e Territórios Semiáridos/PPGESA, do 
Departamento de Ciências Humanas, Campus III da Universidade do Estado da Bahia/UNEB.

É fundamental indicar essa origem para justificar, em certa medida, o tom de oralidade que busquei preservar na escrita. Segui o fio condutor da orientação dada pela organização de que fosse delineada uma reflexão sobre as experiências reais (vivenciadas ou em andamento) e as possíveis interseções entre extensão e diálogo intercultural, com destaque a potencialidades, pontos fortes, pontos críticos e perspectivas. Então, trata-se de um ensaio crítico, em que pretendo que se releve o caráter experiencial.

Como primeiro movimento para construir uma comunicação, visitei o site do evento e li a introdução, de modo que destaco abaixo um fragmento específico que chamou minha atenção:

Novos e urgentes desafios foram postos às instituições de qualquer ordem e nível, a respeito da educação do cidadão, em específico, no contexto do semiárido brasileiro, no qual insurge "[...] uma educação que traz nas suas práticas educativas o desafio de exercitar a contextualização e interdisciplinaridade como estratégia para contrapor-se aos males da pedagogia moderna que se pautou pelos princípios da neutralidade, da formalidade abstrata e da universalidade dos saberes e das práticas." (REIS, 2010, p.10)

A presente proposta tem como escopo refletir uma educação que se fundamenta na própria realidade como ponto de partida e de chegada dos conhecimentos e saberes diversos e de diálogo com as novas dimensões globais, a partir da lógica da interculturalidade. ${ }^{68}$

Li atentamente e busquei compreender o objetivo do encontro, relacionado ao aprofundamento de debates e reflexões sobre novas estratégias de intercâmbio e internacionalização da extensão, envolvendo docentes, pesquisadores/as e discentes de graduação e pós-graduação das Instituições de Ensino Superior de Juazeiro-BA e Petrolina-PE, no Brasil, e de Padova e Rovigo, cidades situadas na Itália.

Como este texto foi sistematizado após o encontro, afirmo sua potência no cumprimento daquilo a que se propôs, lançando questionamentos intrigantes, pelo compartilhamento intercultural, que reverberariam nas minhas próprias práticas, sendo este ensaio, seguramente, um dos frutos.

De minha preparação inicial para estar no Colóquio, importa destacar palavras ou expressões lidas no texto introdutório, que saltaram aos meus sentidos: desafios educacionais - novos e urgentes; educação do cidadão; contextualização; interdisciplinaridade; pedagogia moderna e seus males - neutralidade / formalidade

${ }^{68}$ Grifos da autora. Retirado do site do evento http://www.coloquiobrasilitalia.com/, acessado em 28.10.2019. 
abstrata e universalidade de saberes e práticas; realidade como ponto de partida (e de chegada); diálogo; novas dimensões globais e interculturalidade.

Permiti que tais expressões bailassem com meus pensamentos e sentimentos, revisitando meu percurso experiencial como docente em Instituição de Ensino Superior no sertão do São Francisco. Assim foi se gestando um ensaio, cujo solo foi propriamente o interesse de engendrar, saborear e compartilhar reflexões, de modo bem livre - ainda que com os pés no vivido -, muito mais sobre as fronteiras entre extensão, ensino e pesquisa, o clássico tripé universitário, do que sobre suas delimitações.

De saída, portanto, uma tese: é muito mais fértil o encontro entre tais dimensões do que o artificialismo de sua suposta separabilidade. Da provocação feita a mim, assentei-me na trajetória de pouco mais de uma década de atuação pedagógica, matizada pela inserção em diversos projetos voltados à formação profissional em saúde, os quais explicito brevemente adiante, e urdi um texto na perspectiva de também provocar, ou seja, tirar da calma e do lugar comum, convidando a mais debates e reflexões sobre possibilidades de compreender a relação extensão e diálogo intercultural.

A partir de Houaiss (2009), destaco quatro dos vários sentidos para o vocábulo "cultura", com os quais pretendo entrelaçar minhas reflexões: 1. ação, processo ou efeito de cultivar a terra; 2 . cabedal de conhecimentos de uma pessoa ou grupo social; 3. conjunto de padrões de comportamento, crenças, conhecimentos, costumes etc. que distinguem um grupo social e 4. forma ou etapa evolutiva das tradições e valores intelectuais, morais, espirituais (de um lugar ou período específico).

À medida que participava da mesa e, depois, no exercício de transformar a comunicação oral em texto, fui me dando conta de que a aproximação Brasil-Itália - tendo cada país sua diversidade interna no que se refere a costumes e tradições - é tão somente uma ampliação da relação que já se vive em cada país, em cada região, em cada cidade: o que está vivo é marcado por diversidade, ainda mais por envolver seres humanos, cuja capacidade de agir - relacionada a produzir algo novo, disparar processos, iniciar - é constitutiva de sua condição, como destacado por Arendt (2001).

\section{Práticas revisitadas como fonte para compartilhar alguns caminhos}

Como indicado, para compor essa fala-partilha revisitei minha trajetória docente, na Universidade Federal do Vale do São Francisco/Univasf, instituição que nasce compromissada com o desenvolvimento da região do semiárido nordestino. Optei por 
frisar seis experiências formativas - nas quais exerço e experimento dadas configurações de prática docente -, relacionadas, diretamente ou indiretamente, com extensão.

As experiências em que me respaldo para as reflexões que virão adiante sobre prática docente e o tripé extensão/ensino/pesquisa são as seguintes:

- Orientadora de Estágio Profissionalizante/EP do Curso de Graduação em Psicologia, que ocorre no último ano do curso (nono e décimo períodos): a proposta de EP intitulada "Prática Psicológica em Instituições Públicas" vem sendo desenvolvida desde o segundo semestre de 2008 e acontece integralmente em cenários de aprendizagem situados nas redes públicas de atenção, em especial as do Setor Saúde - ou seja, a clínica-escola se emaranha e materializa nessas redes;

- Tutora do Programa de Educação pelo Trabalho para a Saúde/PET-Saúde: trata-se de programa indutor de mudanças nos contextos da formação profissional em saúde, em nível de graduação, por incentivo do Ministério da Saúde/MS e do Ministério da Educação/MEC. A orientação da mudança é no sentido de aproximar a formação do Sistema Único de Saúde/SUS, em conexão com as necessidades de saúde da população e pela valorização do trabalho em equipe (interprofissional). Pretende articular extensãoensino-pesquisa, promovendo um mergulho de docentes e discentes no mundo do trabalho no SUS, tomado como cenário de aprendizagem, pelo mantra "aproximação ensino-serviço-comunidade". Estando envolvida no PET-Saúde desde o projeto vinculado ao primeiro edital, executado em 2009, acabei sendo transportada para uma marcante experiência, que se desdobrou para além do tempo previsto na comunidade remanescente de quilombo Lage dos Negros (pertencente ao município de Campo Formoso-BA), na edição do PET-Saúde/GraduaSUS (Edital SGTES/MS n 13/2015);

- Tutora e docente de Residências Multiprofissionais em Saúde/RMS: consistem em uma modalidade de ensino de pós-graduação lato sensu, centrada na educação em serviço para as várias categorias profissionais da área de saúde (excetuada a médica), de acordo com a Lei 11.129/2005. São ferramentas políticas que buscam operar o compromisso do SUS de formar profissionais qualificados, como descrito no Artigo 200 da Constituição da República Federativa do Brasil de 1988 (BRASIL, 2016). Passando pelo Residência de Saúde da Família, canalizei o investimento para a Residência de Saúde Mental, desde sua primeira turma, em 2014;

- Militante (docente) do Núcleo de Mobilização Antimanicomial do Sertão/Numans: movimento social em prol da transformação dos modos de cuidado em Saúde Mental no sertão, instituído após o I Fórum de Mobilização Antimanicomial, que ocorreu em 2009, 
por iniciativa de um grupo de discentes de Psicologia da disciplina Saúde Mental I (semestre letivo 2009.1), tendo sido apoiado por edições de projeto de extensão coordenado por mim;

- Docente do Núcleo Temático/NT Políticas da Vida: O NT é um componente curricular próprio da Univasf, que articula docentes de vários cursos, os quais coordenam propostas de aprendizagem valorizando o tripé extensão/ensino/pesquisa a partir de uma dada temática. Tenho estado vinculada ao NT Políticas da Vida, que teve a primeira oferta em 2017.2, com o objetivo geral de "proporcionar vivências sobre valores e princípios ecológicos às comunidades locais, destacadamente àquelas do entorno universitário, em uma região com demandas crescentes de melhora na relação das pessoas - consigo mesmas, entre si e destas com a terra, a água e a biodiversidade, ante as diversas formas de degradação do ambiente e das relações humanas, que têm surgido como subproduto dos desequilíbrios no crescimento econômico no Vale do São Francisco" "69. A fertilidade do NT se revela na possibilidade do aprendizado interprofissional, sobre temas diversos conectados com os modos de vida locais; e

- Coordenadora e pesquisadora do Observatório de Políticas e Cuidado em Saúde do Sertão do Submédio São Francisco/Univasf: o Observatório integra uma rede nacional de Observatórios, coordenada pelo Prof. Emerson Merhy, que "convida a mergulhar nos efeitos da criação das leis, normas, regulamentos, políticas etc. na produção do cuidado em saúde para os/as usuários/as e os/as próprios/as trabalhadores/as, reposicionando a compreensão de avaliação. A proposta fundamental é, partindo da(s) norma(s), instituir espaços de conversação entre os diversos atores que se entrelaçam no contexto da produção do cuidado em uma área específica, aproximando academia-rede de serviços e investindo na composição de redes vivas de cuidados"70.

Conforme compreendo, a partir destas práticas, além da extensão, é também possível fazer uma interlocução com a metodologia de "service-learning" - ou

\footnotetext{
${ }^{69}$ Retirado do Programa da Disciplina, que é coordenada pelo Prof. Alexandre Franca Barreto, docente do Colegiado de Psicologia/Univasf, e que, na oferta do semestre letivo de 2019.2, articula docentes dos Colegiados de Administração, Farmácia, Medicina Veterinária e Psicologia, além de parceria interinstitucional com a Universidade do Estado da Bahia/Uneb, atendendo discentes de seis cursos.

70 Retirado de "OBSERVATÓRIO DE POLÍTICAS E CUIDADO EM SAÚDE DO SERTÃO DO SUBMÉDIO SÃO FRANCISCO: sobre a origem e os horizontes até agora vislumbrados", que consistiu em um texto de apresentação, de caráter polifônico, produzido para o Encontro Nacional de Observatórios, ocorrido em Campo Grande, em 2017, fruto do projeto de pesquisa "Criação de Observatório Microvetorial de Políticas Públicas em Saúde e Educação em Saúde”, coordenado pelo Prof. Emerson Elias Merhy (UFRJ) e financiado pelo CNPq (chamada MCTI/CNPQ/CT- SAÚDE/MS/SCTIE/DECIT nº 41/2013).
} 
aprendizagem em serviço - e a perspectiva de educação intercultural, a partir das conexões indicadas por Milan, Andrian e Bugno (2015). Os autores entrelaçam os três termos - ou proposições - na perspectiva de construção de uma rede de cooperação internacional para desenhar um modelo de estágio universitário, indicando que: a extensão no Brasil destaca o compromisso da universidade com a coesão social e democracia; a metodologia de service learning visa a circularidade de aprendizagem em contextos institucionais diversos, na relação com necessidades sociais e articulando teoria/prática, estudo/trabalho e pensamento/ação e, por fim, a educação intercultural atenta a peculiaridades de cada contexto social, enfatizando a aquisição de competência relacional.

\section{Algumas notas reflexivas a partir da revisitação às práticas docentes tomadas como fonte}

Apresento algumas reflexões que avaliei pertinentes para compartilhamento na interface extensão/diálogo intercultural, em que reconheço uma aproximação com o pensamento de Paulo Freire, pelo destaque que confere a processos de aprendizagem calcados no modo como os sujeitos percebem o mundo, alimentando-se, assim, da relação com sujeitos concretos, que habitam os cenários da vida de formas marcadas pela singularidade. Compreendo que isto deve ser objeto de interesse do/a docente-educador/a.

Cultivo, inclusive, a Educação Popular em Saúde como uma de minhas referências, tendo sido uma das primeiras paixões no aprofundamento de minha relação com a atuação no Sistema Único de Saúde/SUS. Trata-se de um modo de compreensão e intervenção que se tornou política pública no contexto do SUS, fundamentado no ideário freireano, que defende um aprendizado encarnado no mundo, (re)conhecendo o solo em que se pisa e legitimando os diversos saberes e práticas populares. A Política Nacional de Educação Popular em Saúde tem, como princípios, o diálogo, a amorosidade, a problematização, a construção compartilhada do conhecimento, a emancipação e o compromisso com a construção do projeto democrático e popular (BRASIL, 2013).

Em projetos de aproximação com a comunidade, como nas ações extensionistas, importa valorizar genuinamente o que se encontra nos cenários vivos. Daí a necessidade e a potência de refletir permanentemente sobre o intuito dessa aproximação universidadecomunidade, pondo em questão o desejo de domínio - inclusive pelo saber tecnicista que pode guiar as ações. Para aprofundamento dessa reflexão, permanecem atuais e 
relevantes as provocações freireanas apresentadas em "Extensão ou comunicação?" (FREIRE, 1983).

Em sintonia com essa vereda compreensiva, a primeira nota pode ser assim referida - a experiência como fonte primeva. O ponto de que se parte na proposição de ações extensionistas precisa ser o que se encontra nos cenários em que se pisa. Desse ato - o encontro - brotam desalojamentos, em que a teoria (um dado modo de ver, como sugere seu sentido originário) pode surgir para ampliar compreensões, mas não como solução do que aparece como "problema". Ainda que sejam necessárias sistematizações dentro dos limites ensino/pesquisa/extensão, no contato com o "campo" se revela muito mais uma mistura desses "campos", em intensa e fértil articulação ensino-pesquisaextensão. Isso implica perceber as fronteiras muito mais como lugares de passagem do que como muros limitantes.

Cabe, inclusive, uma rápida menção à importância de reconhecer que a compreensão do tripé se sustenta de mau jeito, desdobrando-se em valorização e investimentos desequilibrados de cada eixo. Em geral, a pesquisa goza de privilégios - e status diferenciado. Contudo, projetos de pesquisa significativos costumam derivar de imersões em cenários reais da vida, ou seja, da aproximação viabilizada em geral pela extensão. Aliás, nas pesquisas de campo, um dado compromisso com a colheita e os resultados precisa ser assumido para além de uma relação utilitarista. E, nisto, ganha vulto a consideração da relevância social de estudos e, sobretudo, seus efeitos nas vidas das pessoas.

Assim, a extensão se delineia por sua relação íntima com o mundo da vida - na cidade, na comunidade, na região - sendo este o solo onde se situa o próprio adubo para atividades de ensino e projetos de pesquisa que assumem uma orientação político e eticamente implicada. Nessa aproximação, tece-se experiência - dos aprendizes e do/a docente -, tomada como força motriz para produção e compartilhamento de conhecimento relevante, especialmente com quem se encontra nos cenários da vida real. São, portanto, cenários da vida real mobilizando saberes, capacidades, potências.

Em Larrosa (2015), descubro um modo de compreender experiência que incrementa essa mirada para a extensão - bem como ao ensino e à pesquisa. Experiência não é o que acontece, mas o que acontece em cada pessoa, ou seja, como as coisas vividas repercutem nelas. Não há como garantir que algo aconteça, contudo, promover oportunidade para isso parece-me um modo viável de praticar pedagogia. Algo que 
acontece vai além do cognitivo, e sua elaboração compreensiva demanda pausa - e reflexão.

Pautar processos de ensino-aprendizagem fundados na valorização da experiência - ou de sua possibilidade -, em um redimensionamento do tripé extensão/ensino/pesquisa como região de fronteira ${ }^{71}$, tem se configurado como uma via potente em minha prática docente. Afinal de contas, a educação se destina a transformar, a introduzir diferenças e, quiçá, a produzir canto:

A experiência é algo que (nos) acontece e que às vezes treme, ou vibra, algo que nos faz pensar, algo que nos faz sofrer ou gozar, algo que luta pela expressão, e que às vezes, algumas vezes, quando cai em mãos de alguém capaz de dar forma a esse tremor, então, somente então, se converte em canto. (LARROSA, 2015, op. cit., p. 10)

Nas origens da definição de seguir a trilha de valorização da experiência, reconheço algumas referências filosóficas, respaldando-me na perspectiva fenomenológica, que destaca a dimensão relacional na produção de compreensão acerca dos fenômenos do mundo e da vida. Recorro à analítica do sentido (CRITELLI, 2007), uma articulação metodológica possível ao se optar por uma atitude fenomenológica, fundada em elementos do pensamento de Martin Heidegger e Hannah Arendt. Destaco, a partir disso, a compreensão heideggeriana de humano, como Da-sein - ser-aí, ser-nomundo -, constituindo-se como clareira, abertura, em sua tarefa fundante: cuidar de ser. De Arendt, ressalto o agir político, pela e na convivência entre humanos, na dupla inserção de pluralidade e singularidade que marca a nossa condição.

A segunda nota remete ao como fazer, em que ressalto a cartografia como um modus operandi, que dá ênfase à inversão hodos/meta, pela intenção de dar relevo ao caminhar, pisar para conhecer, melar-se de mundo na tentativa de compreendê-lo e, só a partir disso, traçar objetivos que façam sentido para as pessoas com que encontramos. Fui me aproximando da cartografia inicialmente no encontro com projetos de extensão e pesquisa de Morato (1999), retomando Rolnik (1987) e, aportando, provisoriamente, em Passos; Kastrup; Escóssia (2010).

Uma miríade de proposições vai fazendo sentido nas ações propostas: a compreensão de um corpo que vibra pelo trânsito em territórios vivos (ROLNIK, op. cit.)

\footnotetext{
${ }^{71}$ Uso essa expressão inspirada na discussão de Henriette T. P. Morato sobre Aconselhamento Psicológico, uma prática própria do/a psicólogo/a, que o caracteriza como "lugar de fronteira", por se ofertar como possibilidade de campo de conhecimento interdisciplinar/transdisciplinar. Em: MORATO, Henriette T. P. (org.) Aconselhamento centrado na pessoa: novos desafios. São Paulo: Casa do Psicólogo, 1999.
} 
a necessidade de reconhecimento e valorização do contexto/chão em que se pisa; a perspectiva de tomar encontro como método, valorizando a micropolítica do trabalho vivo em ato (MERHY, 2015), recolhendo os seus efeitos pela afecções produzidas, como indicado na discussão sobre ética em Espinosa (SPINOZA, 2009); a força da ação transdisciplinar como produção coletiva (CABRAL; ANDRADE, 2012).

Assim foi se consolidando a compreensão de que conhecer e aprender precisa ter sabor. Saber pode ter sabor. No trânsito experiencial, ao longo dos encontros promovidos nos territórios, vale a metáfora de viagem e a escrita de diários cartográficos. É importante regatar a riqueza da narrativa do que se vive, considerando-se muito fértil a articulação feita por Benjamin entre experiência e narrativa (BENJAMIN, 1996).

Corpos - que podem vibrar, porque vivos, que afetam e se deixam afetar, porque ativos - se lançam nos territórios, cujas peculiaridades precisam ser conhecidas para além da observação, antes de qualquer proposta interventiva. Por esta via, a invenção de qualquer proposta - se gestada no entre, no estar com, no conhecer pelo encontro - ganha mais força e pertinência - ou pertencimento. Estando em campo, presentes, não somos meros observadores. Toda presença é intrusiva, provoca alterações onde se insere - e aí já se ressalta uma dimensão interventiva (MORATO, SCHMIDT, ANDRADE, 2007). Ou de interferências (FIGUEIREDO et al., 2019).

A terceira e última nota remete a algo que pode ser chamado de ativação do sensível $^{72}$, que discuto a partir da figura do caleidoscópio e de sua potência:

A metáfora do caleidoscópio - do grego kalós (belo) + ềdos (forma) + -skopeîn (olhar) (HOUAISS, 2009) - parece responder bem à tentativa de compreender um processo de pesquisa, tomado como prática: nos giros em campo, você olha (encontra) diversas configurações, que se apresentam enigmáticas a princípio, demandando interpretações. Cada configuração se produz a partir do encontro entre quem olha e o que ou quem é olhado e muitos arranjos são possíveis nesse entremeio, a partir da movimentação no território. Não se trata de perceber algo já dado, que independe do ato de olhar. O que é visto está na relação com o próprio ato de olhar. (CABRAL; MORATO, 2019, p. 89/90)

Aqui a palavra pesquisa pode ser substituída por extensão ou ensino. Um olhar caleidoscópico se matiza no encontro, em que o inusitado, o imponderável, o inesperado

\footnotetext{
${ }^{72}$ Essa expressão é utilizada em proposta de oficina ofertada no $13^{\circ}$ Congresso Internacional da Rede Unida, em 2018, intitulada "Ativação do sensível em processos formativos: o desafio de despertar outras sensibilidades para a produção do cuidado em Saúde Mental/Atenção Psicossocial”, produção compartilhada com outras três parceiras de trabalho - Ana Kalliny de Souza Severo, Ana Karenina de Melo Arraes Amorim e Flávia Helena Miranda de A. Freire.
} 
pode acontecer - e acontece. Importa tentar produzir visibilidade ao teor desses encontros e de suas repercussões, pelo compartilhamento de narrativas, em geral, interpretativas. Em imersões e experiências promovidas por atividades de extensão (ou ensino ou pesquisa), além do sentido ético e político a ser delineado, entra ainda a dimensão estética, no compromisso com o que se produz de efeitos e com sua análise: como produzir visibilidade ao que brotou como afecção dos encontros, ao que se produziu no encontro dos olhares?

Em interlocução com Rancière (2005), destaca-se a importância de sempre pensar sobre a relação estética/política, que se estabelece em um dado encontro, situado em um dado contexto, na relação com pluralidade das práticas humanas, em especial quando aparece algo diferente do que - racionalmente - se esperava, tendo em vista que as pessoas estão em um mundo sensível comum.

A perspectiva assumida não é a de buscar a verdade: não se está em um quarto preto, de olhos vendados, a se buscar um gato preto. Verdades são produzidas no contexto relacional, nas negociações, atravessadas por elementos subjetivos diversos, que incluem, mas também se situam muito além da racionalidade.

Em direção à finalização, as notas reflexivas sobre extensão/diálogo intercultural partem do seguinte chão: estamos no mundo, somos corpos no mundo, vivendo encontros, produzindo compreensões em torno disso. Esse também é o solo das provocações em torno das fronteiras do tripé - extensão é pesquisa? extensão é ensino? - ou posto de outro modo - extensão produz/ensina conhecimento? Defendo a fertilidade da fronteirametáfora, a partir de que se compreende que saberes e práticas dos núcleos disciplinares - brotado dos campos científicos diversos - e saberes e práticas populares se cruzam, se borram, se afetam, se interpenetram. É nesse trânsito pelas fronteiras que se aprende e se produz novos saberes mais pertinentes - quicá impertinentes -, porque pertencentes à vida tal como vivida, em sua imanência cotidiana. É nesse terreno que a universidade precisa permanentemente se reinventar, atualizando seu compromisso social.

\section{Reflexões para levar adiante uma educação transformadora pela valorização da extensão e do diálogo entre culturas}

Ações de extensão precisam compor uma formação cidadã, uma educação que transforma pela conexão com a vida, em sua multiplicidade constitutiva. Pela aproximação universidade-campo, revela-se uma pletora de configurações do real, em 
que importa retomar nossa condição fundamental: interrogação acerca de quem somos e de como levamos - ou podemos levar - a vida adiante.

Retomando os sentidos de cultura (HOUAISS, op. cit.), destaco que em processos de aprendizagem, em contextos de extensão, ensino ou pesquisa, precisamos cultivar constantemente o solo em que transitamos, reconhecendo e legitimando o mosaico singular de conhecimentos, práticas, padrões de comportamento, crenças, conhecimentos, costumes, tradições e valores intelectuais, morais, espirituais de uma pessoa ou grupo social. Somente com esta base, qualquer proposta interventiva pode fazer sentido, em processos diversos de negociações, o que é próprio das atividades humanas. Por em questão os valores, no sentido de avaliar se estão a favor ou contra a expansão da vida, como propõe Nietzsche (2009), é um caminho que abre novas possibilidades de levar adiante a existência entre humanos/as de modo inclusivo. Entre culturas de diferentes países, ou dentro de um mesmo país... Somos seres sempre diversos/as.

Como fertilidade desse modo, destaco a própria intenção de manter viva a condição de interrogação que marca o humano, sem se deixar seduzir por totalitarismos de qualquer ordem. Nesse sentido, cabe sempre questionar: conhecer para que? intervir para que e a pedido de quem? Aí se ressalta a força da aproximação de cenários "reais" como mote para aprender e construir no coletivo.

Dentre os pontos críticos, a busca de equilibrar o tripé e reconhecer o valor da fronteira, por meio de valorização efetiva, em termos de investimento financeiro, produção e divulgação. Nesse sentido, a Resolução n ${ }^{\circ}$ 7/2018, do Ministério da Educação, que define a "curricularização" da extensão na Educação Superior, é um sopro de revitalização, cujos contornos estão ainda em delineamento, sendo um desafio.

Assim, as perspectivas são de expansão da extensão e de diálogo intercultural potencializando ensino e pesquisa -, em sintonia com os desafios postos pelas configurações locais e mundiais. No sertão e em qualquer lugar, temos sempre muitas culturas envolvidas. A disponibilidade de encontrar e se relacionar genuinamente e de modo respeitoso com a alteridade que marca a condição humana - seres singulares e plurais - requer, indubitavelmente, a marca da ousadia.

\section{Referências bibliográficas}

ANDRADE, Ângela N.; MORATO, Henriette T. P.; SCHMIDT, Maria Luisa S. Pesquisa interventiva em instituição: etnografia, cartografia e genealogia. In: RODRIGUES, Maria 
M. P., MENANDRO, Paulo R. M. (Org.) Lógicas metodológicas: trajetos de pesquisa em psicologia. Vitória: GM Gráfica Editora, 2007. p. 193-206.

BENJAMIN, Walter. O narrador: considerações sobre a obra de Nikolai Leskov. In: . Magia e técnica, arte e política: ensaios sobre literatura e história da cultura.7. ed. São Paulo: Brasiliense, 1996. Obras escolhidas, v. 1. p. 197-221.

BRASIL. Constituição da República Federativa do Brasil: texto constitucional promulgado em 5 de outubro de 1988, com as alterações determinadas pelas Emendas Constitucionais de Revisão nos 1 a 6/94, pelas Emendas Constitucionais nos 1/92 a 91/2016 e pelo Decreto Legislativo no 186/2008. - Brasília: Senado Federal, Coordenação de Edições Técnicas, 2016.

BRASIL. MINISTÉRIO DA SAÚDE. Portaria GM no 2.761, de 19 de novembro de 2013. Institui a Política Nacional de Educação Popular em Saúde no âmbito do Sistema Único de Saúde (PNEPS-SUS). Disponível em: http://bvsms.saude.gov.br/bvs/saudelegis/gm/2013/prt2761_19_11_2013.html. Acesso em: 07.11.2019.

BRASIL. MINISTÉRIO DA EDUCAÇÃO. Conselho Nacional de Educação/Câmara de Educação Superior. Resolução $\mathbf{n}^{\mathbf{0}} \mathbf{7}$, de 18 de dezembro de 2018. Estabelece as Diretrizes para a Extensão na Educação Superior Brasileira e regimenta o disposto na Meta 12.7 da Lei no 13.005/2014, que aprova o Plano Nacional de Educação - PNE 20142024 e dá outras providências. Publicada no Diário Oficial da União, de 19/12/2018. Disponível em:

in.gov.br/materia/-/asset_publisher/Kujrw0TZC2Mb/content/id/55877808. Acesso em 07.11.2019.

CABRAL, B. E. B; ANDRADE, A. N. Ação transdisciplinar como produção coletiva: percussões e repercussões no trabalho em equipes de saúde. In: PINHEIRO, R.; SILVEIRA, R.; LOFEGO, J.; SILVA JÚNIOR, A. G. (orgs.). Integralidade sem fronteiras: itinerários de justiça, formativos e de gestão na busca por cuidado. Rio de Janeiro: CEPESC/IMS/UERJ/ABRASCO, 2012, p. 229-244

CABRAL, B. E. B.; MORATO, H. T. P. Redimensionando o valor da questão-bússola no horizonte da produção de conhecimento: para onde uma pesquisa pode apontar? In: CABRAL, B. E. B.; SZYMANSKI, L.; MOREIRA, M. I. B.; SCHMIDT, M. L. S. (orgs.) Práticas em pesquisa e pesquisa como prática: experimentações em psicologia. Curitiba: CRV, 2019.

CRITELLI, D. M. Analítica do sentido: uma aproximação e interpretação do real de orientação fenomenológica. $2^{a}$. Ed. São Paulo: Brasiliense, 2007.

FIGUEIREDO, Eluana B. L.; ANDRADE, Eliane O.; MUNIZ, Marcela P.; ABRAHÃO, Ana Lúcia. Revista Brasileira de Enfermagem; 72(2): 571-576, Mar.-Abr. 2019.

FREIRE, Paulo. Extensão ou comunicação? Tradução de Rosisca Darcy de Oliveira. $7^{\text {a }}$ ed. Rio de Janeiro, Paz e Terra, 1983, 93 p. 
HOUAISS, Antônio; VILLAR, Mauro de S.; FRANCO, Francisco M. de M. Dicionário Houaiss da língua portuguesa. Rio de Janeiro, 2009.

LARROSA, J. Tremores: escritos sobre experiência. Trad. Cristina Antunes; joão Wanderly Geraldi. 1 ${ }^{\mathrm{a}}$. Ed.; 1 ${ }^{\mathrm{a}}$ reimp., Belo Horizonte: Autêntica Editora, 2015.

MERHY, E. Educação Permanente em Movimento - uma política de reconhecimento e cooperação, ativando os encontros do cotidiano no mundo do trabalho em saúde, questões para os gestores, trabalhadores e quem mais quiser se ver nisso. Saúde em Redes. 2015; 1 (1): 07-14.

MILAN G., ANDRIAN N., BUGNO L., INTEREURISLAND - INTERsectoral, 'Extensão Universitária', Research, Interculture and Service Learning, in 'III Jornada de Investigadores sobre Aprendzagem y Servicio', CLAYSS, Buenos Aires, 2015, pp 325-330.

MORATO, H. T. P. Aconselhamento psicológico: uma passagem para a transdisciplinaridade. In: MORATO, Henriette T. P. (org) Aconselhamento psicológico centrado na pessoa: novos desafios. São Paulo: Casa do Psicólogo, 1999. p. 61-88.

NIETZSCHE, F. Genealogia da moral. São Paulo: Companhia das Letras, 2009.

PASSOS, Eduardo; KASTRUP, Virgínia; ESCÓSSIA, Liliana da. (orgs) Pistas do método da cartografia: pesquisa-intervenção e produção de subjetividade, Porto Alegre: Sulina, 2010.

RANCIÈRE, J. A partilha do sensível. Trad. Mônica Costa Neto. São Paulo: Exo experimental org.: Ed. 34, 2005.

ROLNIK, Suely. Cartografia ou de como pensar com o corpo vibrátil. 1987. Disponível em:

https://www.pucsp.br/nucleodesubjetividade/Textos/SUELY/pensarvibratil.pdf Acesso em 07.11.2019.

ROSA, João Guimarães. Tutaméia. Rio de Janeiro: Nova Fronteira, 2001.

SPINOZA. Ética. Trad. Tomaz Tadeu. Belo Horizonte: Autêntica Editora, 2009. 